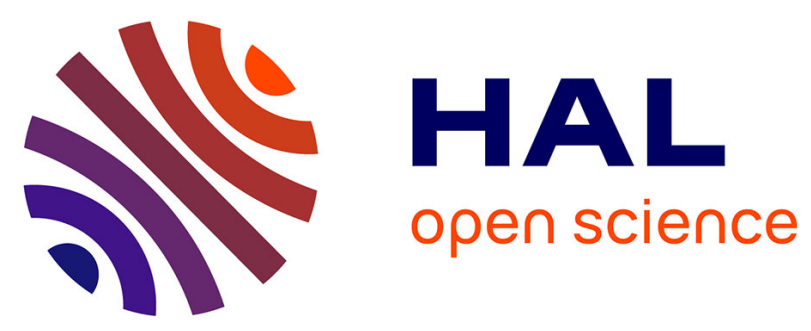

\title{
Burden of rotavirus infections in Liguria, northern Italy: hospitalisations and potential savings by vaccination
}

\author{
D. Panatto, D. Amicizia, R. Giacchino, A. Tacchella, A. R. Natalizia, G. \\ Melioli, R. Bandettini, P. Pietro, M. C. Diana, R. Gasparini
}

\section{- To cite this version:}

D. Panatto, D. Amicizia, R. Giacchino, A. Tacchella, A. R. Natalizia, et al.. Burden of rotavirus infections in Liguria, northern Italy: hospitalisations and potential savings by vaccination. European Journal of Clinical Microbiology and Infectious Diseases, 2011, 30 (8), pp.957-964. 10.1007/s10096011-1180-7 . hal-00666339

\section{HAL Id: hal-00666339 \\ https://hal.science/hal-00666339}

Submitted on 4 Feb 2012

HAL is a multi-disciplinary open access archive for the deposit and dissemination of scientific research documents, whether they are published or not. The documents may come from teaching and research institutions in France or abroad, or from public or private research centers.
L'archive ouverte pluridisciplinaire HAL, est destinée au dépôt et à la diffusion de documents scientifiques de niveau recherche, publiés ou non, émanant des établissements d'enseignement et de recherche français ou étrangers, des laboratoires publics ou privés. 


\section{BURDEN OF ROTAVIRUS INFECTIONS IN LIGURIA (NORTHERN ITALY): HOSPITALIZATIONS}

AND POTENTIAL SAVING BY VACCINATION

D. Panatto $^{1 *}$, D. Amicizia ${ }^{1}$, R. Giacchino ${ }^{2}$, A. Tacchella ${ }^{2}$, A. R. Natalizia ${ }^{2}$, G. Melioli ${ }^{3}$, R. Bandettini ${ }^{3}$, P. Di Pietro $^{4}$, M. C. Diana ${ }^{4}$, R. Gasparini ${ }^{1}$

Short running head: Burden of Rotavirus hospitalisations in Italy

${ }^{1}$ Department of Health Science, University of Genoa, Genoa (Italy)

${ }^{2}$ Unit of Infectious Diseases, G. Gaslini Children’s Hospital, Genoa (Italy)

${ }^{3}$ Clinical Pathology and Microbiology Laboratories, G. Gaslini Children's Hospital, Genoa (Italy)

${ }^{4}$ Emergency Department of Paediatrics, G. Gaslini Children's Hospital, Genoa (Italy)

* Corresponding author: Donatella Panatto

Department of Health Science, University of Genoa, Via Pastore 1, 16132 Genoa (Italy)

e-mail: panatto@unige.it

Tel.: +39 0103538109; fax: +390103538541 


\section{Abstract}

Purpose We evaluated the rates of gastroenteritis admissions to the emergency department and of rotavirusrelated hospitalisations in children $\leq 5$ years in 2006 at an Italian paediatric hospital; we calculated the number of rotavirus cases avoidable through the universal vaccination of children.

Methods Epidemiological data were extracted from the Data Elaboration Centre. To calculate the hospitalisation rate due to rotavirus, the virus was sought in the faeces of children hospitalised for acute gastroenteritis by means of rapid immunochromatographic assay.

Results Emergency department admissions due to gastroenteritis numbered 2396 (11.58\% of total admissions). Of these, 276 children (11.52\%) were examined and then sent home; 1286 (53.67\%) were kept in short observation and $776(32.38 \%)$ were hospitalised. In $27.83 \%$ of hospitalised cases, the rotavirus test proved positive. The RV hospitalization rate was 55 per 10000 children $\leq 5$ years in Genoa in 2006 . In $85.6 \%$ of hospitalised patients with community-acquired rotavirus infection, the disease was severe.

Conclusions The number of avoidable cases confirmed that the vaccination of children $\leq 1$ year of age could reduce the burden of rotavirus infection, especially with regard to hospitalisation (45 per 10000 children $\leq 5$ years) and admissions to short observation (85 per 10000), generating benefits for Italian healthcare system.

Key words: Rotavirus, hospitalisation, vaccination, gastroenteritis 


\section{Text}

\section{Introduction}

Rotavirus gastroenteritis (RVGE) is a major cause of infantile gastroenteritis worldwide and is responsible for high rates of mortality and morbidity in developing countries, where hygiene conditions and living standards are low; in industrialized countries, it remains a common cause of medical consultations and hospital admissions [1] [2], indicating that improved sanitation does not reduce the circulation of the virus.

The clinical picture varies considerably and can be serious, comprising severe diarrhoea, electrolyte disorders and dehydration. The risk of hospitalisation is high in children under 5 years old, particularly in the 6-24-month age-group [3]. Comparison with other agents of gastroenteritis indicates that rotavirus (RV) is more frequently associated with severe symptoms [4] [5].

The infection is passed from person to person through the oro-faecal route, but transmission probably occurs through droplets, too [6]. Moreover, the virus is very difficult to eradicate and remains viable on dry surfaces for 1 - 10 days and on human hands for at least 4 hours [7] [8]. These characteristics can explain why RV is a cause of nosocomial infections [9].

It has been recognized that diarrhoea remains a leading cause of morbidity among US children, accounting for approximately $10 \%$ of all inpatient admissions of US children younger than 5 years of age [4] [10]. SorianoGabarrò estimated that Europe has 3.6 million cases per year among children under 5 years of age, 87,000 admissions and about 700,000 medical consultations; however, mortality caused by rotavirus disease is low: about 241 deaths per year [11].

Two rotavirus vaccines have recently been licensed in Italy. These could be an efficacious means of reducing the burden of the infection and the costs to the healthcare system and society, rendering RV illness a vaccinepreventable disease [12].

There is no gastroenteritis surveillance system in Italy. Moreover, data on the burden of infection are needed in order to understand the potential benefits of introducing universal rotavirus vaccination in children under 1 year of age. We therefore conducted a retrospective study to evaluate the rates of gastroenteritis admissions to the Emergency Department (ED) and of rotavirus-related hospitalisation in children under 5 years of age. We calculated the number of RV cases that could potentially be avoided through the universal vaccination of children. 


\section{Materials and methods}

Approval for this study was granted by the Local Ethics Committee.

Study population

A retrospective epidemiological study of admissions to the ED and hospitalisations of children $\leq 5$ years with acute gastroenteritis (AGE) was carried out at Giannina Gaslini Children's Hospital in Genoa (Northern Italy). Giannina Gaslini Hospital is the only paediatric hospital covering the metropolitan area of Genoa, which has 39,176 children aged less than 5 years [13].

The study analyzed epidemiological data from 2006.

Case definition of subjects admitted to the ED

Gastroenteritis was defined as the presence of diarrhoea ( $\geq 3$ watery stools within a period of $24 \mathrm{~h}$ ) and/or vomiting, with or without fever [14]. All subjects recruited met the clinical case definition.

Nosocomial case definition

When the onset of gastroenteritis (presence of diarrhoea $\geq 3$ watery stools within a period of $24 \mathrm{~h}$ and/or vomiting, with or without fever [14]) occurred after three days of hospitalisation, nosocomial infection was assumed. Nosocomial RV infections were included in the study.

Admissions to ED and Hospitalisations

The annual number of admissions to the ED due to gastroenteritis and the hospitalisation rate for gastrointestinal illness were collected by extracting these data from the Data Elaboration Centre. Giannina Gaslini Hospital has a Data Elaboration Centre which registers the diagnosis on admission, triage code and diagnosis on discharge. The medical records of the RV-positive children were collected and analyzed.

To calculate the hospitalisation rate due to RV, the virus was sought in the faeces of children hospitalised for acute gastroenteritis. 
Laboratory assay

The samples of faeces collected from hospitalised children were analyzed by means of rapid immunochromatographic assay (Combi-strip Coris BioConcept, Belgium) in order to detect RV.

Evaluation of the cases potentially avoided by universal vaccination

We calculated the number of admissions to the ED, admissions to Short Observation (SO) and hospitalisations that could be avoided by universal RV vaccination. Subjects with severe AGE who declined hospitalisation were not considered in the calculation of cases potentially avoided by vaccination.

In order to calculate the potentially avoided cases, it is essential to know the severity of the disease, as the efficacy of the RV vaccine varies according to disease severity [15]. In hospitalised children, disease severity was graded by means of the 20-point Vesikari scale [16]. As it was not possible to score disease severity in subjects in either the ED or the SO, these cases were regarded as moderate, in accordance with the literature [15].

As stool samples from children examined in the ED or kept in SO are not routinely collected, RV positivity was estimated by using data from the literature, particularly the results obtained by Forster [17].

The parameters used in the analysis of the potentially avoided cases in the basic case and in the sensitivity analysis range are reported in Table 1 . We performed separate sensitivity analyses for the following parameters: variation in RV-positive cases in the ED, in SO and in hospitalisation with community-acquired RV infection, vaccine efficacy and coverage. It was not possible to calculate the rate of nosocomial RV infections, as we do not know the denominator, namely the total number of cases of nosocomial gastroenteritis.

The potentially avoided cases were calculated by means of the following formula:

$\mathrm{A}=\mathrm{N} * \mathrm{E} * \mathrm{C}$

Where $\mathrm{A}=$ number avoided cases; $\mathrm{N}=$ number of $\mathrm{RV}$-positive cases; $\mathrm{E}=$ vaccine efficacy; $\mathrm{C}=$ coverage rate.

\section{Cost evaluation}

The costs associated to emergency room admission for gastroenteritis, hospitalisation and nosocomial RV infection were estimated by using Gaslini Hospital's tariffs (June 30, 2006).

The cost of emergency room admission was estimated as $€ 141$ (\$ 180.30). The cost of SO admission was 
estimated as $€ 1000$ (\$ 1278.77). The DRG tariffs associated to all hospitalisations due to RV disease were analysed and the average cost was fixed at $€ 1478$ (\$ 1890.02). The cost of nosocomial RV infection was estimated as $€ 2000$ (\$2557.54), considering the average length of hospitalisation.

Statistical analysis

Statistical analysis was performed by means of the SPSS 15.0 statistical package for Windows (SPSS, Chicago USA). We estimated the Relative Risk by Odds Ratio calculation by means of Fisher's exact test. The level of significance adopted was $\mathrm{p} \leq 0.05$. Quantitative variables were expressed as means, medians and standard deviations (SD), and qualitative variables as frequency and percentage with $95 \%$ confidence intervals.

Excel (Microsoft) software was used for sensitivity analyses. 


\section{Results}

In 2006, total admissions to the paediatric ED were 20,690; total admissions to the ED due to gastroenteritis numbered 2396 (11.58\% of total admissions, 95\% CI 10.29-12.86). Of these, 276 children $(11.52 \%$, 95\% CI 10.24-12.79) were only examined and then sent home; 1286 (53.67\%, 95\% CI 51.67-55.66) were kept in SO; for 834 children $(34.80 \%, 95 \%$ CI 32.90-36.71) hospitalisation was requested. Of these, $776(32.38 \%, 95 \%$ CI 30.51-34.25) were hospitalised and 58 declined hospitalisation (2.42\%, 95\% CI 1.80-3.03).

The 776 hospitalised children were tested for RV. In 27.83\% (95\% CI 24.67-30.98) (216 patients: 110 females and 106 males), the RV test proved positive. Therefore, the RV hospitalization rate was 55 per 10000 children aged less than 5 years in Genoa in 2006. Table 2 shows the distribution of RV-positive and -negative cases by age-group among the hospitalised children with community-acquired RV infection. We analyzed the medical records of RV-positive children with community-acquired infection and nosocomial infection; 22 cases (12 females and 10 males) were classified as nosocomial infections because the onset of gastrointestinal symptoms occurred 3 or more days after hospitalisation due to other causes.

We also registered admission diagnoses in children hospitalised with community-acquired RV infection. Briefly, the admission diagnosis was dehydration in 70 subjects (36.08\%, 95\% CI 29.32-42.83), vomiting in 36 (18.55\%, 95\% CI 13.08-24.01), nausea and vomiting in 2 (1.03\%, 95\% CI 0-2.45), diarrhoea in $33(17.01 \%$, 95\% CI 11.72-22.29), fever in $28(14.43 \%, 95 \%$ CI 9.48-19.37), gastroenteritis in $82(42.26 \%, 95 \%$ CI $35.31-49.21)$ and other (abdominal pain, rhinitis, cough) in 37 (19.07\%, 95\% CI 13.6-24.6); it should be borne in mind that an individual child may have more than one admission diagnosis.

The average age of children hospitalised with community-acquired RV infection was 27.79 months \pm 16.64 SD (24.1 median age), and the length of hospitalisation was 4.18 days \pm 3.8 SD. The average age of hospitalised children with nosocomial RV infection was 23.61 months $\pm 17.17 \mathrm{SD}$ (22.55 median age). The RV disease prolonged their hospital stay by an average of 4.4 days \pm 2.7 in comparison with the main diagnosis on hospital admission and the main diagnosis on discharge.

Table 3 reports the Vesikari scores and clinical characteristics of children with community-acquired versus nosocomial RV gastroenteritis. The cases were broken down according to severity by means of the method described by Vesikari [16]; on the basis of disease severity, the number of cases avoided through vaccination was computed by taking into account the different efficacy of the vaccine.

The mean Vesikari score in patients with community-acquired RV infections was 12.93 (range 9-20); 185 $(85.6 \%)$ patients had a score $\geq 11$, which is generally regarded as indicating severe disease. In patients with 
nosocomial infections, the mean Vesikari score was 12.41 (range 6-16) and 18 (82\%) had a score $\geq 11$.

We also registered the main and secondary discharge diagnoses in children hospitalised with communityacquired RV infection. Briefly, with regard to the main diagnosis on discharge, an ICD00861 code (Rotavirus intestinal infection) was assigned to 50 patients $(23.14 \%, 95 \%$ CI 17.51-28.76); ICD0090, 0091,0092 or 0093 (diarrhoea/probable infectious enteritis) to 24 (11.11\%, 95\% CI 6.92-15.30); ICD2765 (dehydration) to 28 (12.96\%, 95\% CI 8.48-17.43); ICD2769 (fluid and electrolyte disorder) to 52 (24.07\%, 95\% CI 18.37-29.77); and other causes to $62(28.71 \%, 95 \%$ CI $22.67-34.74)$. Secondary diagnoses on discharge were coded as ICD00861 (Rotavirus intestinal infection) in 91 cases $(42.12 \%, 95 \%$ CI 35.53-48.70); ICD00869 (other viral enteritis) in 8 (3.71\%, 95\% CI 1.18-6.23); ICD0090, 0091, 0092 or 0093 (diarrhoea/probable infectious enteritis) in $22(10.18 \%, 95 \%$ CI 6.14-14.21); ICD2765 (dehydration) in 32 (14.81\%, 95\% CI 10.07-19.54); ICD2769 (fluid and electrolyte disorder) in $3(1.39 \%, 95 \%$ CI 0.00-2.95); ICD78701 (nausea and vomiting) in $4(1.85 \%$, 95\% CI 0.00-3.652); and other causes in 56 (25.92\%, 95\% CI 20.07-31.76).

The number of RVGE cases was highest towards the end of winter and at the beginning of spring, though cases were diagnosed throughout the year; a clear predominance was seen during February, March and April.

Figure $1 \mathrm{~A}$ shows the variation in the number of cases potentially avoided through universal RV vaccination on varying the number of RV-positive cases. Considering the base case, 71 cases examined in the ED, 332 cases in the SO unit and 176 hospitalised cases could be avoided (corresponding to 45 hospitalizations per 10000 children aged less than 5 years in Genoa in 2006). Figure 1 B also shows the variation in the number of cases avoided on the basis of the efficacy of the RV vaccine. Figure $1 \mathrm{C}$ shows the variation in the number of cases avoided on the basis of the coverage rate of RV vaccination. Considering the base case, the cost of RVGE was calculated as $€ 800,079$. The universal vaccination of the children under 1 year of age living in the study area (6,529 subjects) would cost the healthcare system a maximum of $€ 457,030$ ( $€ 70,00$ per vaccination cycle), considering a $100 \%$ coverage rate.

\section{Discussion}

The availability of RV vaccines has prompted many researchers to evaluate the epidemiological and economic burden of RV disease. In Italy, however, it is difficult to make an accurate assessment of the incidence of RVGE, as no surveillance system is in place.

The results of our study confirm that acute gastroenteritis, particularly RVGE, is a major cause of ED admission and hospitalisation among children below 5 years of age. The disease burden was seen to be heavy and similar to 
the percentages reported in other Italian studies [17] [18]. Giaquinto et al. [5] reported a heavier impact; they found that $40 \%$ of acute enteritis cases in children under 5 years were caused by RV, the virus being responsible for $68 \%$ of hospitalisations, $61 \%$ of ED examinations and $33 \%$ of cases of primary care in the Padua area (Northern Italy). Direct comparison is difficult, owing to differences in study designs, laboratory tests and study periods. It should be noted that the magnitude of RV epidemics varies from year to year; indeed, in our study period (2006) the circulation of RV was low. Comparison of our findings with those of the latest European studies reveals a different RV burden on ED admissions and hospitalisations. This variability can be attributed to many factors, such as different policies of health-system access and cultural factors that influence the tendency to seek healthcare [17] [19].

In our study, the mean hospital stay among children with community-acquired RV was 4.18 days; this is similar to the European mean [17] [20] [21]. The age-class at greatest risk of hospitalisation for community-acquired RVGE was 0-23 months, while the distribution of nosocomial cases was similar in all age-classes.

Complications were rare and no deaths due to RV disease occurred. However, the Vesikari scores revealed that $85.6 \%$ of hospitalised patients with community-acquired infection suffered severe disease and received fluid infusion.

Our data show that RV coded discharges capture only a part of all RV hospitalisations. Other authors [18] [22] have confirmed this finding. Physicians recorded the ICD code 00861 on the main discharge diagnosis form in only $23.14 \%$ of RV-positive cases with community-acquired infection, and on the secondary discharge diagnosis form in $42.12 \%$; the RV code was attributed to only $65.26 \%$ of RV-positive cases. Comparison with the data from the discharge diagnosis database alone, which is the most easily accessible official data source on hospitalisation, reveals that RV-associated hospitalisation is underestimated. Laboratory data indicated that the burden on RV hospitalisation was close to reality.

A clear seasonal distribution emerged, with the greatest incidence occurring at the end of winter and at the beginning of spring (between March and April); a lower circulation was registered during the other months of the year. These data are similar to those of other studies [19] [21] [23]. Given that other viruses, such as Respiratory Syncytial Virus (RSV) and Influenza, mainly spread during the winter, the additional upsurge in RVGE exacerbates the problem of overcrowding in emergency departments and paediatric wards [24] [25].

The results of our study suggest that RV vaccination (90\% coverage) could eliminate 45 hospitalizations per 10000 children aged less than 5 years. However, on basis of the literature, and of the results of our sensitivity analysis, we can affirm that RV vaccination could eliminate a maximum (100\% coverage) of 64 hospitalizations per 10000 children aged less than 5 years. 
In routine hospital practice, laboratory tests are not frequently used to confirm RV infection in children examined in the ED and/or kept in SO; for this reason, the proportion of diarrhoeal episodes due to RV cannot be directly determined. Testing for RV infection in faeces is only carried out in hospitalised children.

Our calculation of the number of avoidable cases confirmed that universal vaccination would reduce the impact of RV infection on ED admissions, hospitalisations and admissions to the SO unit; similar finding have been reported by other authors [26] [27]. These results are confirmed by recent data on surveillance in the USA, where the introduction of RV vaccination into the paediatric immunization schedule has reduced the burden of RV gastroenteritis [28].

When evaluating the introduction of a new vaccination programme, it is necessary to consider the clinical, economic and social damage caused by the disease. RV illness has a considerable impact on society, as it mainly strikes children under 5 years of age, who are dependent on their families (e.g. productivity loss due to the absenteeism from work of one parent). RV disease does not only cause suffering for the infected child, but also anxiety and stress for the family. Furthermore, the universal vaccination of children $<1$ year would not entail a significant additional workload for healthcare services, as the vaccine can be administered simultaneously with other vaccines and vaccination can be inserted into the vaccination sessions scheduled for infants aged 3 and 5 months [29].

Our study has the limitation that we did not collect the medical records of the RV-negative hospitalised children, which would have enabled us to assess the severity of their gastroenteritis and to compare the severity of RV disease with that of disease caused by other etiological agents of diarrhoea.

In conclusion, our study confirms that acute RV gastroenteritis is a major public health problem and that it has a heavy impact on Italian healthcare services and on society. This research adds information on the demographic and clinical features of RV disease in Italy and the results could be used to evaluate the change in the incidence of RV disease as a result of the introduction of vaccination.

On the basis of our estimate of the potentially avoidable cases of RV, it is reasonable to expect that a universal vaccination programme would substantially reduce the burden of RV on the healthcare system in Italy, particularly on hospitalisations. 


\section{Acknowledgments}

The authors thank: Manuela Rescali for her support in data collection; Roberto Scali and Roberto Arrighi for their assistance in extracting epidemiological data; Emanuela Piccotti for data collection in the Emergency Department, and Paolo Ferrari, Anna Pellettieri, Antonella Formiga, Laura Fenu and Cinzia Gatti for their technical support.

Thanks go to GlaxoSmithKline, who partially supported this study by providing two educational grants. 


\section{References}

1. Parashar UD, Gibson CJ, Bresse JS, Glass RI (2006) Rotavirus and severe childhood diarrhea. Emerg Infect Dis $12: 304-6$

2. Parashar UD, Hummelman EG, Bresee JS, Miller MA, Glass RI (2003) Global illness and deaths caused by rotavirus disease in children. Emerg Infect Dis 9:565-572

3. Dennehy PH (2000) Transmission of rotavirus and other enteric pathogens in the home. Pediatr Infect Dis J 19(Suppl 10):103-105

4. Bernstein DI (2009) Rotavirus overview. Pediatr Infect Dis J 28(Suppl 3):50-53

5. Giaquinto C, Callegaro S, Andreola B et al. (2008) Prospective study of the burden of acute gastroenteritis and rotavirus gastroenteritis in children less than 5 years of age, in Padova, Italy. Infection 36:351-57

6. Fischer T, Bresee JS, Glass RI (2004) Rotavirus vaccines and the prevention of hospital-acquired diarrhea in children. Vaccine 22(Suppl 1):49-54

7. Ansari SA, Springthorpe VS, Sattar SA, Tostowaryk W, Wells GA (1991) Comparison of cloth, paper, and warm air drying in eliminating viruses and bacteria from washed hands. Am J Infect Control 19:243-9

8. Ansari SA, Springthorpe VS, Sattar SA (1991) Survival and vehicular spread of human rotaviruses: possible relation to seasonality of outbreaks. Rev Infect Dis 13:448-461

9. Berner R, Schumacher RF, Hameister S, Forster J (1999) Occurrence and impact of community-acquired and nosocomial rotavirus infections a hospital-based study over 10 years. Acta Paediatr 88:48-52

10. Charles MD, Holman RC, Curns AT, Parashar UD, Glass RI, Bresee JS (2006) Hospitalisations associated with rotavirus gastroenteritis in the United States, 1993-2002. Pediatr Infect Dis J 25:489-493

11. Soriano-Gabarró M, Mrukowicz J, Vesikari T, Verstraeten T (2006) Burden of rotavirus disease in European Union countries. Pediatr Infect Dis J 25(Suppl 1):7-S11

12. Guarino A, Ansaldi F, Ugazio A et al (2008) Italian Pediatrician's consensus statement on anti-Rotavirus vaccines. Minerva Pediatr 60:3-16

13. ISTAT 14th Italian Population Census, October 21, 2001. http://www.demoistat.it. Accessed 2 March 2009

14. Coffin SE, Elser J, Marchant C et al 2006 Impact of acute rotavirus gastroenteritis on pediatric outpatient practices in the United States. Pediatr Infect Dis J 25:584-9

15. Vesikari T, Karvonen A, Prymula R (2007) Efficacy of human rotavirus vaccine against rotavirus gastroenteritis during the first 2 years of life in European infants: randomised, double-blind controlled study. Lancet 370:1757-1763

16. Ruuska T, Vesikari T (1990) Rotavirus disease in Finnish children: use of numerical scores for clinical 
severity of diarrhoeal episodes. Scand J Infect Dis 22:259-267

17. Forster J, Guarino A, Parez N et al (2009) Hospital-based surveillance to estimate the burden of rotavirus gastroenteritis among European children younger than 5 years of age. Pediatrics 123: 393-400

18. Marsella M, Raimondi L, Bergamini M et al (2009) Epidemiology of rotavirus-associated hospital admissions in the province of Ferrara, Italy. Eur J Pediatr 168:1423-7

19. López-de-Andrés A, Jiménez-García R, Carrasco-Garrido P, Alvaro-Meca A, Galarza PG, de Miguel AG (2008) Hospitalisations associated with rotavirus gastroenteritis in Spain, 2001-2005. BMC Public Health 8:109

20. Waisbourd-Zinman O, Ben-Ziony S, Solter E, Scherf E, Samra Z, Ashkenazi S (2009) Hospitalisations for nosocomial rotavirus gastroenteritis in a tertiary pediatric center: A 4-year prospective study. Am J Infect Control 37:465-9

21. Wildi-Runge S, Allemann S, Schaad UB, Heininger U (2009) A 4-year study on clinical characteristics of children hospitalised with rotavirus gastroenteritis. Eur J Pediatr 168:1343-8

22. Marchetti F, Assael B, Gabutti G et al (2009) Monitoring the rate of hospitalisation before rotavirus immunization in Italy utilizing ICD9-CM regional databases. Hum Vaccin 10:1-5

23. Rendi-Wagner P, Kundi M, Mikolasek A et al (2006) Active hospital-based surveillance of rotavirus diarrhea in Austrian children, period 1997 to 2003 . Wien Klin Wochenschr118: 280-85

24. Le Roux P, Marshall B, Toutain F et al (2004) Nosocomial viral infections in a pediatric service: example of rotaviral gastroenteritis and respiratory syncytial viral bronchiolitis. Arch Pediatr 11:908-915

25. Thuret A, Patural H, Berthelot P et al (2004) Prospective follow-up of hospital-acquired diarrhoea in 28 paediatric wards of the south-east part of France during a winter season. Pathol Biol 52: 131-7

26. Huet F, Largeron N, Trichard M, Miadi-Fargier H, Jasso-Mosqueda G (2007) Burden of paediatric rotavirus gastroenteritis and potential benefits of a universal rotavirus vaccination programme with RotaTeq in France. Vaccine 25:6348-6358

27. Panatto D, Amicizia D, Ansaldi F et al (2009) Burden of rotavirus disease and cost-effectiveness of universal vaccination in the Province of Genoa (Northern Italy). Vaccine 27:3450-53

28. Centers for Disease Control and Prevention (CDC) (2008). Delayed onset and diminished magnitude of rotavirus activity-United States, November 2007-May 2008. MMWR Morbidity and Mortality Weekly Report $57: 697-700$

29. Word Health Organization (WHO) (2009). Rotavirus vaccines: an update. Weekly Epidemiological Report $51-52: 533-540$ 


\section{Caption to Figure 1}

A - Sensitivity analysis: number of cases avoided by RV vaccination on varying the number of RVpositive cases

B - Sensitivity analysis: number of cases avoided on varying the efficacy of the RV vaccine

C - Sensitivity analysis: number of cases avoided on varying RV vaccination coverage 

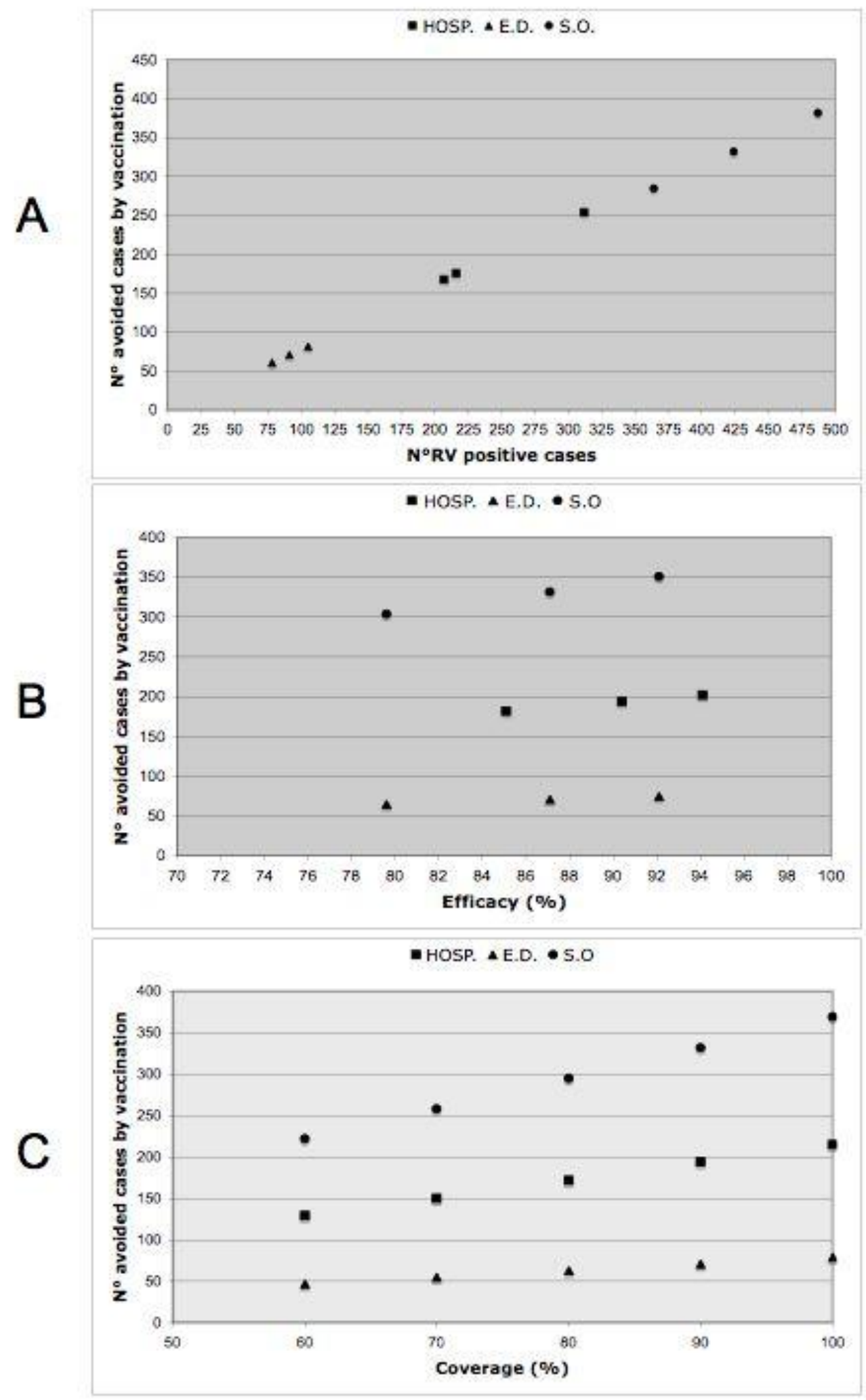
Table 1: Parameters used in the analysis of the potentially avoided cases in the basic case and in the sensitivity analysis range

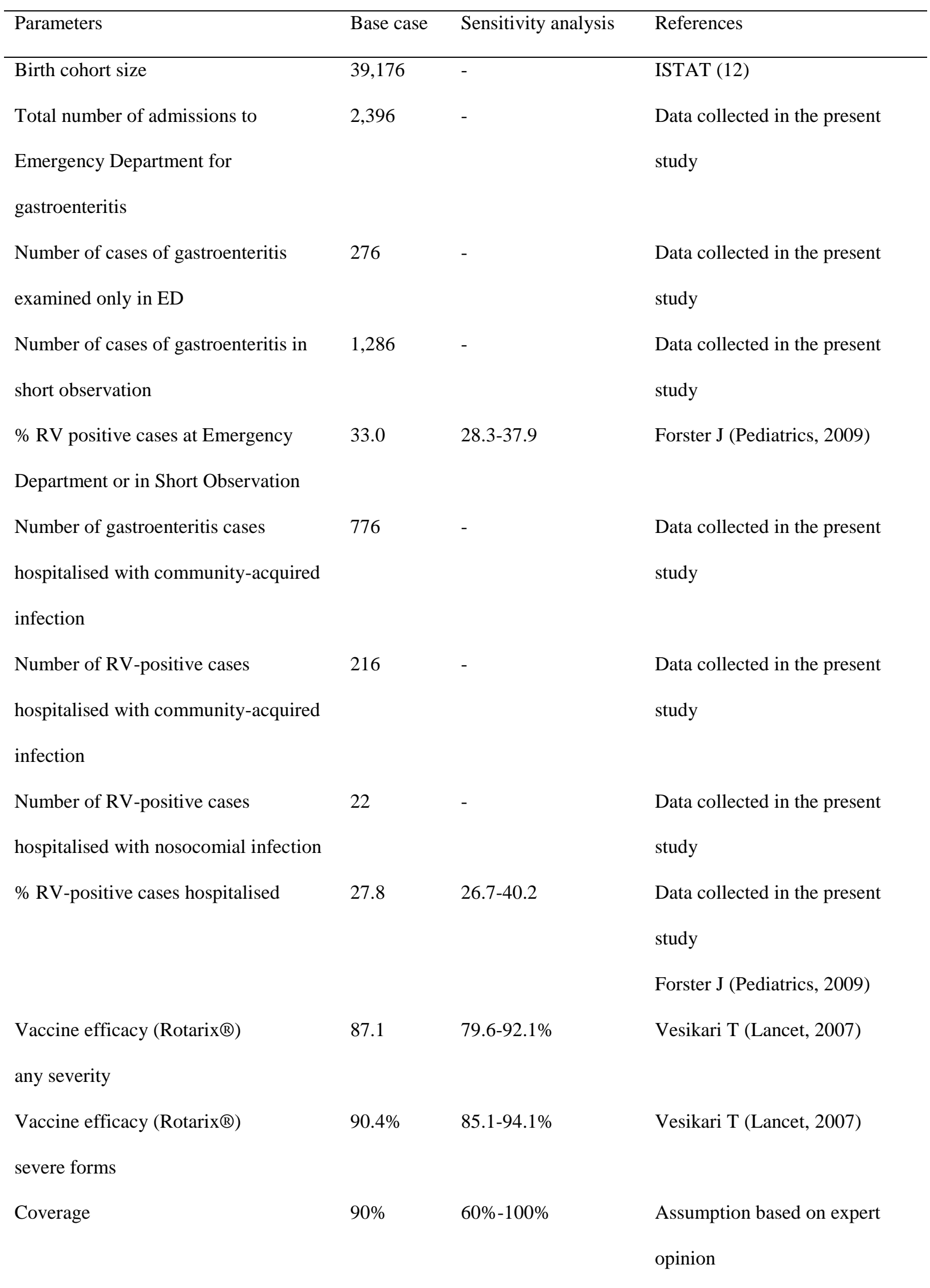


TABLE 2: Distribution of RV-positive and -negative cases by age-group among the hospitalised children

\begin{tabular}{|c|c|c|c|c|c|c|}
\hline Age-class & $\mathrm{N}^{\circ}$ positive & $\%$ & CI $(95 \%)$ & $\mathrm{N}^{\circ}$ negative & $\%$ & CI $(95 \%)$ \\
\hline (Months) & cases & & & cases & & \\
\hline $0-11$ & 40 & 18.5 & $13.3-23.7$ & 244 & 43.6 & $39.9-47.6$ \\
\hline $12-23$ & 64 & 29.6 & $23.5-35.7$ & 130 & 23.2 & $19.7-26.6$ \\
\hline $24-35$ & 39 & 18.1 & $13.0-23.2$ & 88 & 15.7 & $12.6-18.7$ \\
\hline $36-47$ & 28 & 13.0 & $8.5-17.5$ & 46 & 8.2 & $5.9-10.4$ \\
\hline $48-59$ & 45 & 20.8 & $15.4-26.2$ & 52 & 9.3 & $4.7-8.8$ \\
\hline Total & 216 & 100 & 100 & 560 & 100 & 100 \\
\hline
\end{tabular}


TABLE 3: Vesikari score and comparison of clinical characteristics of community-acquired versus nosocomial RV gastroenteritis

\begin{tabular}{|c|c|c|c|c|c|}
\hline \multirow[t]{3}{*}{ Signs and symptoms } & Points & RVGE community & RVGE & \multirow[t]{3}{*}{ OR } & \multirow[t]{3}{*}{$\mathrm{P}$ value } \\
\hline & Vesikari & acquired & \multirow[t]{2}{*}{ Nosocomial } & & \\
\hline & Score & $\left(\mathrm{N}^{\circ} 194\right)$ & & & \\
\hline \multicolumn{6}{|l|}{ Duration of vomiting } \\
\hline \multicolumn{6}{|l|}{ (days) } \\
\hline 0 & 0 & $64 / 216$ & $3 / 22$ & & \\
\hline 1 & 1 & $76 / 216$ & $10 / 22$ & & \\
\hline 2 & 2 & $38 / 216$ & $7 / 22$ & & \\
\hline$\geq 3$ & 3 & $38 / 216$ & $2 / 22$ & $1.3(0.5-3.1)$ & 0.6 \\
\hline \multicolumn{6}{|c|}{ Vomiting: frequency/day } \\
\hline 0 & 0 & $64 / 216$ & $3 / 22$ & & \\
\hline 1 & 1 & $88 / 216$ & $13 / 22$ & & \\
\hline $2-4$ & 2 & $42 / 216$ & $6 / 22$ & & \\
\hline$\geq 5$ & 3 & $22 / 216$ & $0 / 22$ & $0.9(0.3-2.4)$ & 1 \\
\hline \multicolumn{6}{|l|}{ Duration of diarrhoea } \\
\hline \multicolumn{6}{|l|}{ (days) } \\
\hline 0 & 0 & $35 / 216$ & $2 / 22$ & & \\
\hline $1-4$ & 1 & $121 / 216$ & $10 / 22$ & & \\
\hline 5 & 2 & $28 / 216$ & $5 / 22$ & & \\
\hline$\geq 6$ & 3 & $32 / 216$ & $5 / 22$ & $2.2(0.8-5.2)$ & 0.1 \\
\hline \multicolumn{6}{|c|}{ Diarrhoea: frequency/day } \\
\hline 0 & 0 & $35 / 216$ & $2 / 22$ & & \\
\hline $1-3$ & 1 & $126 / 216$ & $11 / 22$ & & \\
\hline $4-5$ & 2 & $32 / 216$ & $5 / 22$ & & \\
\hline$\geq 6$ & 3 & $23 / 216$ & $4 / 22$ & $2.0(0.8-0.5)$ & 0.1 \\
\hline \multicolumn{6}{|l|}{ Body temperature ${ }^{\circ} \mathrm{C}$} \\
\hline$<37.1$ & 0 & $19 / 216$ & $3 / 22$ & & \\
\hline $37.1-38.4$ & 1 & $123 / 216$ & $19 / 22$ & & \\
\hline
\end{tabular}


38.5-38.9

$\geq 39$

Dehydration

None

Mild or moderate (1-5\%)

Severe $(\geq 6 \%)$

Treatment

None

Rehydration

Hospitalisation
2

3

0

2

0

1

2
$45 / 216$

$29 / 216$

$7 / 216$

$180 / 216$

$29 / 216$

$0 / 216$

$216 / 216$

$22 / 22$

$216 / 216$
$0 / 22$

$0 / 22$

$0.8(0.2-2.8)$

0.7

1 